\title{
DỨBin
}

Level 3

Volume 12

Issue 1 March, 2015

Article 7

3-2015

\section{Development of a Framework to Facilitate a Collaborative Peer Learning 2:1 Model of Practice Placement Education}

Ann-Marie Lynam

Departments of Clinical Medicine and Occupational Therapy, Trinity College Dublin

Clare Corish

Technological University Dublin, clare.corish@tudublin.ie

Deirdre Connolly

Departments of Clinical Medicine and Occupational Therapy, Trinity College Dublin

Follow this and additional works at: https://arrow.tudublin.ie/level3

Part of the Entrepreneurial and Small Business Operations Commons

\section{Recommended Citation}

Lynam, Ann-Marie; Corish, Clare; and Connolly, Deirdre (2015) "Development of a Framework to Facilitate a Collaborative Peer Learning 2:1 Model of Practice Placement Education," Level 3: Vol. 12: Iss. 1, Article 7. doi:10.21427/D78M8X

Available at: https://arrow.tudublin.ie/level3/vol12/iss1/7

This Article is brought to you for free and open access by the Current Publications at ARROW@TU Dublin. It has been accepted for inclusion in Level 3 by an authorized editor of ARROW@TU Dublin. For more information, please contact arrow.admin@tudublin.ie, aisling.coyne@tudublin.ie,gerard.connolly@tudublin.ie.

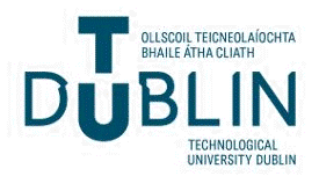




\title{
ORIGINAL RESEARCH
}

\section{Development of a framework to facilitate a collaborative peer learning 2:1 model of practice placement education}

\author{
Ann-Marie LYNAM, $^{1}$ Clare CORISH ${ }^{2}$ and Deirdre CONNOLLY ${ }^{3}$ \\ ${ }^{1}$ Departments of Clinical Medicine and ${ }^{3}$ Occupational Therapy, Trinity College Dublin, and ${ }^{2}$ School of Biological \\ Sciences, Dublin Institute of Technology, Dublin, Ireland
}

\begin{abstract}
Aim: The educational approach towards practice placement education in health-related disciplines has changed in recent years. The use of collaborative or peer learning models has increased, associated with positive effects on desired outcomes such as learning, competence and reflective practice. At present, there is little published literature on the implementation or use of such models in dietetics practice placement education. The aim of this study was to conduct a pilot study of a collaborative peer learning 2 students to 1 educator (2:1 model).

Methods: Experienced practice placement educators from four clinical sites in the discipline of dietetics in the Republic of Ireland were invited to participate in the study and form an advisory group. Feedback from this group was used to inform the design and development of a framework to guide the wider implementation of the 2:1 model. Results: Feedback from the pilot study was largely positive, with all four sites willing to facilitate a 2:1 model again. The main recommendation was that the practice placement educators require more practical information on the implementation of a 2:1 model, particularly the facilitation of the peer feedback process. In response to this feedback, the Lynam framework was designed, which is the focus of this paper.

Conclusions: This pilot study of a 2:1 model in dietetics practice placement education informed the design and development of a framework for implementation of the model. Further research into the use of the 2:1 model for practice placement education and the effectiveness of the Lynam framework to guide the implementation of this model is required.
\end{abstract}

Key words: 2:1 model, collaborative learning, practice placement education.

\section{Introduction}

Practice placement education (PPE) is an integral component in the attainment of competence in professional programmes for all health-related disciplines. ${ }^{1}$ A number of education models are currently used to provide PPE within these programmes, and opinion differs as to which is superior, ${ }^{2}$ or indeed whether 'one size fits all'. In keeping with European standards, ${ }^{3}$ compliance with competency criteria based on those specified for entry level dietitians eligible

A.-M. Lynam, MSc, Principal Investigator, Practice Education Coordinator

D. Connolly, PhD, Head of Department, Associate Professor,

Academic Supervisor.

C. Corish, PhD, Programme Director, Associate Professor, Academic Supervisor.

Correspondence: A.-M. Lynam, Clinical Medicine, University of Dublin, Trinity College Dublin, Trinity Centre for Health Sciences, St James's Hospital, James's St, Dublin 8, Ireland. Tel.: +353-868352775, Fax: +353-1-4542043; Email: annmarie.lynam@tcd.ie

Accepted April 2014 for membership of the professional body (Irish Nutrition and Dietetic Institute $)^{4}$ is mandatory for successful completion of PPE.

Collaborative learning may be defined as 'two or more students working collaboratively under the supervision and guidance of one primary instructor. ${ }^{5}$ It is sometimes referred to as the 2:1 model, because it involves one practice placement educator, hereafter referred to as educator, working with two or more students. ${ }^{6}$ It serves as an umbrella term for a number of educational approaches involving 'joint intellectual effort by students and teachers together'. Collaborative learning also provides the theoretical framework that underpins the concept of peer learning. ${ }^{7}$ Peer learning or peer-assisted learning may be defined as 'to get knowledge through study, experience or teaching of an equal', ${ }^{8}$ or as 'peers helping each other to learn'. Although learning is deemed to be more effective when there is collaboration between students, ${ }^{9}$ an Australian review concluded that insufficient evidence exists to promote one model of collaborative or peer learning over another. It is clear, however, that there is insufficient evidence to promote the traditional $1: 1$ 
model of PPE as being a 'gold standard', which collaborative models must match in their outcomes. ${ }^{2}$

Although the 1:1 model remains the most frequently used approach to PPE, a pedagogical shift from this traditional didactic model of PPE towards a more facilitative studentdirected model ${ }^{10}$ has become apparent in the UK, USA, Canada and Australia, particularly in the disciplines of occupational therapy and physiotherapy., ${ }^{5,11-15}$ This approach encourages students to direct their own learning, engage in the feedback process and utilise reflective practice. This change in approach, together with a widespread shortage of clinical placements, has led to an increased interest in the use of collaborative or peer learning models of PPE within these disciplines. ${ }^{16}$ In the published literature, however, significant anomalies exist in the terminology that is used to describe the various education strategies employed during PPE and their underlying theories or learning principles, which can make direct comparisons difficult. ${ }^{17}$ For the purposes of this research, a collaborative, peer learning 2:1 model, hereafter referred to as 2:1 model, was the approach piloted. Although little published literature on the use of such approaches within the dietetics setting is available ${ }^{18}$ it seems reasonable to extraopolate the findings from similar health-related disciplines to the dietetics setting.

The advantages of introducing a 2:1 model are manifold. The observation and feedback skills of the students are improved, ${ }^{19}$ there is increased time for reflective practice ${ }^{13}$ and opportunity to practise skills on each other. ${ }^{12,20}$ Increased efficiency in educators' involvement with students as a group, rather than separately, has been reported, resulting in reduction of repetition, which may address the issue of shortage of clinical placements. ${ }^{21}$ Student independence is increased, reducing reliance on the educator to answer superficial questions, provide social support and constant supervision, even in the early stages of PPE. ${ }^{14,22,23}$ Overall, the quality of the student and educator experience is improved, while achieving desirable trends in patient care, clinical education and professional development. ${ }^{1,14}$ Disadvantages of the introduction of a 2:1 model include the requirement for increased planning and organisation preplacement, and for the completion of assessment documentation for two students simultaneously. ${ }^{11,20,24,25}$ New skills are required by educators to work with two students simultaneously, including facilitation of peer learning, ${ }^{11}$ which may not always be used optimally. ${ }^{9}$ There is the potential for students being 'mismatched' in personality or ability ${ }^{15,19}$ and educator time and caseload must be shared between two students. ${ }^{24,25}$ Support from other staff may also be required. ${ }^{24}$ However, with careful planning, potential barriers to using a 2:1 model are surmountable, while the advantages make this effort worthwhile. $9,11,14,15,19$

Across the health-related disciplines, little has been published on how to implement collaborative or peer education models. ${ }^{15}$ One Australian model within dietetics PPE incorporates regular rotation of student pairs in a strict time frame, with staged progression of dietetic tasks undertaken within one clinical setting. Such a model does not provide a feasible framework for implementing a 2:1 model in the Irish setting as students rotate to different geographical locations and change between hospital and primary care (community) settings at various times during PPE. ${ }^{23}$

The aim of this pilot study was to explore the use of a 2:1 model in dietetics PPE, with a view to possible implementation of the model in the Irish setting. The 2:1 model used incorporated elements of peer learning, including peer observation and peer feedback (peer review) based on the theoretical framework of collaborative learning, and more specifically the social interdependence theory. ${ }^{26}$ This exists when there is a common goal between group members and the accomplishments of each member are affected by the others. Positive interdependence occurs when the goal is shared, so that achievement of the goal is dependent on the actions of all members.

\section{Methods}

In 2010, four out of 44 dietetics PPE sites in the Republic of Ireland were approached to trial a 2:1 model. The sites were mixed, incorporating two urban teaching hospitals, one primary care (Community) dietetics department, and one smaller regional hospital. These sites were chosen so that dietitians who were experienced practice placement educators would be able to act as key informants or an advisory group, on whether the higher education institution (HEI) should implement the 2:1 model within dietetics PPE in Ireland. Educators at each site were supplied with literature on collaborative and peer learning and were given guidelines for facilitating peer observation and the peer feedback process within a 2:1 model. No additional preparation over that normally provided prior to the 26-week PPE was undertaken with the year 4 students who had already been allocated to the sites chosen.

Following completion of PPE using the 2:1 model, the practice education coordinator (HEI-based) held a discussion group ${ }^{27}$ with the advisory group members at each of the four sites. Written notes were made during these discussions, including verbatim quotes from discussion group participants which were returned to participants for feedback and comment. ${ }^{28}$ These transcripts were read and blindly categorised using qualitative techniques by a colleague not involved in the study, in order to address the issue of bias as recommended in the literature. ${ }^{29,30}$ Full ethical approval for this research was granted by the School of Medicine, Trinity College Dublin, Ethics Committee.

\section{Results}

While all four sites reported that they would use the 2:1 model again, the strongest recommendation from the advisory group was that specific guidelines on how to optimally facilitate two students during patient consultations were required. Students and educators also required training on scheduling regular time within or between each patient consultation for engaging in and facilitating the peer feedback process; 'it's hard not to slip back into teacher-mode', 'it takes practice to balance feedback between the two [stu- 
dents]', 'the students need to know what is expected of them'. Practical sessions on engaging in and facilitating the peer feedback process, practising peer observation (including scripting) and reflecting on their own practice were recommended. Furthermore, students and educators required training sessions on the theories and principles underpinning the 2:1 model.

Given the feedback from the advisory group and concerns expressed in the literature about the process of applying a 2:1 model, practical information on how to implement the model was required. As the number of weeks spent in each clinical site providing PPE in the Irish setting varies, a framework with a broad scope to guide students and educators through the process was needed.

\section{Discussion}

In keeping with feedback from the advisory group on the level of support required, the structure to support the facilitation of peer feedback and reflective practice was prescriptive. Similar needs have been reported in the literature ${ }^{21,24}$ with many educators citing difficulties with having to 'unlearn' previously learnt methods of giving feedback. ${ }^{18}$ Understanding how to facilitate a collaborative model predicts successful 2:1 placement more accurately than previous experience as an educator. ${ }^{1}$ Zavadek et al. (1995) reporting on two case studies, concluded that in-depth preparation of educators contributed to success using a 2:1 model. ${ }^{11}$

The Lynam framework describes in a step-wise manner the organisation of the two students and for the educator during three different scenarios, incorporating both inpatient and outpatient consultations, as was recommended by the advisory group. Insufficient detail on implementing a collaborative model within the published research across the health-related disciplines has previously been reported as a barrier to implementing the model. ${ }^{15,18}$

The staged design of the framework allocates protected time for the students to partake in the feedback process and in reflective practice at regular intervals, which is also supported by the literature. ${ }^{19,24,25}$ In order to work successfully with the framework, educators need to have identified suitable patients for two students. The framework encourages educators to allow the student pair to gather information together without the educator present at least once or twice per day, which gives the educator up to two hours daily to undertake other work. This advantage has been highlighted in previous literature. ${ }^{19,21,31}$

Within any 2:1 model of PPE, 1:1 time should be regularly scheduled and this has been included in the framework. This is important for student independence, assessment and transparency, and reduces the difficulty for educators in assessing the competence of paired students individually, which has been documented extensively in the literature. ${ }^{11,25}$

As well as being guided by feedback from the advisory group and published literature, the framework structure is underpinned by theoretical educational frameworks such as the social interdependence theory. ${ }^{26}$ Scenario 1 of the frame- work differs from scenarios 2 and 3 , in that it involves the sharing of tasks between the students to reach a shared goal. This is based on the premise that 'individuals encourage and facilitate each other's efforts to learn'. ${ }^{32}$ Conversely, in scenarios 2 and 3, each individual student may reach their goal, independent of the actions of the other student. The peer feedback process remains however, to allow the students to facilitate each other in the attainment of their goal.

Figure 1 represents an illustration of the Lynam framework for the facilitation of two students simultaneously during the different stages of a patient consultation process for three different patient consultation scenarios. Scenarios 1 and 2 are used in an inpatient setting, while scenario 3 is used in an outpatient clinic setting. At the beginning of PPE, the students observe the educator for two patient consultations. The students should then progress to conducting the introduction and information gathering parts of the consultation (stages 1-4). For all three scenarios, it is explained to the patient at the beginning of the consultation that only one student will be communicating with the patient. The other student is there as an observer, to learn from his/her peer and to give feedback after the consultation. As with a 1:1 model, the complexity of the patient case should be considered, and students should commence with less complex patients, when possible.

Again in keeping with the feedback from the advisory group and extensive reports in the literature on the importance of the underlying skills to facilitate a 2:1 model, ${ }^{1,11,18,24}$ an interactive education module has now been developed for educators and students before the introduction of the framework on a wider basis. This module includes the theories underpinning collaborative learning, including the social interdependence theory, ${ }^{26}$ group learning, ${ }^{22}$ behavioural change ${ }^{33}$ and reflective practice. ${ }^{34}$ Practical skills based on these theories, including facilitation of and participation in the practice of peer observation (including scripting), the peer feedback process and reflective practice have been incorporated into the module. The module has been designed to be delivered to educators and students in a small group teaching setting to promote optimal learning and participation, including practise, role play and observation and feedback opportunities. When delivering the module to students, participants are organised into groups of 3 , rotating the role of 'patient', 'dietitian' and 'observer' for mock patient consultations. After each participant practises the 'dietitian' role, a debriefing or feedback session occurs, led by an academic facilitator trained in feedback skills. The 'observer' is responsible for leading the peer feedback process, and his/her role is to script the consultation, focusing on the words of the dietitian. This is an example of active observation; another example is for the 'observer' to observe and document a particular aspect of the 'dietitian's' performance during the consultation, which is then discussed afterwards. After a role play exercise, the 'observer' reads out the script in an objective, non-judgemental manner. The academic facilitator asks the 'dietitian' for feedback on his/her performance in a structured way, that is one to two of either positive feedback or constructive criticism. Examples 


\section{The Lynam Framework for a (2:1) Model}

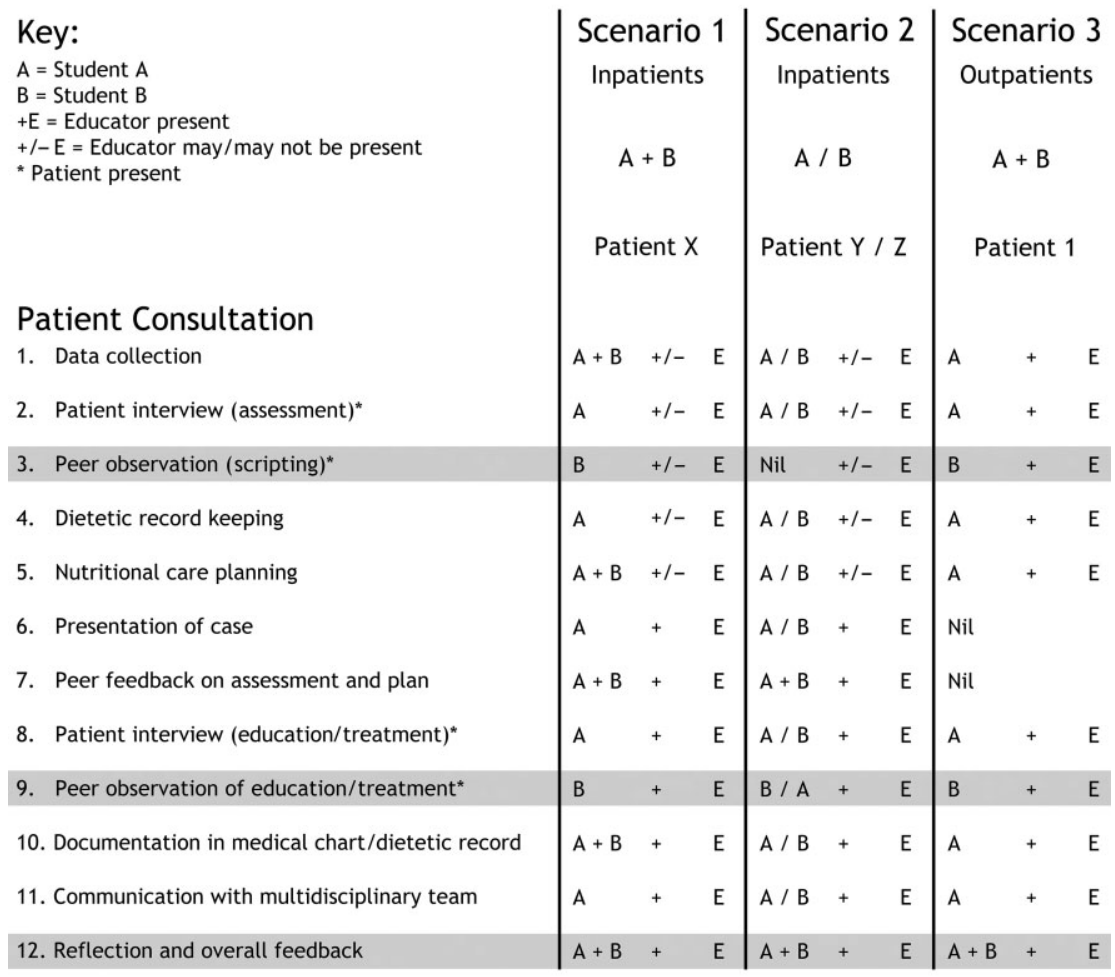

Note: For Scenarios 1 and 3, students rotate being student 'A' for consecutive patients

Figure 1 The Lynam framework for a (2:1) model.

include 'Dietitian, tell me one thing that went well for you during the consultation (and why) and one thing that you would change (and why)'. The 'patient' is then asked to give feedback on the performance of the 'dietitian' in a similar structured manner. For example, 'Patient, tell me two things that the "dietitian" said/did that you believe worked well, and suggest two other pieces of information that the dietitian could have looked for from you during the assessment stage'. The academic facilitator may have observed some of the role play and may be able to comment further if required. The academic facilitator also ensures that the feedback remains structured, focused and balanced. The 'dietitian' may then practise completing a reflective log on his/her performance, answering questions such as 'what went well?', 'what would you have done differently?' and 'what did you learn from the experience?'. The delivery of the module to educators is similar, the participants are organised into groups of three, rotating the role of 'Student A', 'Student B' and 'dietitian' for mock student feedback sessions based on hypothetical patient consultation scenarios. Each participant practises the 'dietitian' role of facilitating the feedback session in which both 'Student A' and 'Student B' are required to partake. As with the module delivered to students, each participant is asked to identify a point of positive feedback and/or constructive criticism. Afterwards, a debriefing or feedback session occurs, led by the academic facilitator, who has an observer role during the sessions.
Within the framework, scenario 1 may be used in any acute, rehabilitation or residential setting. Both students (A $\&$ B) go to see the same patient, and work through stages $1-5$ of the patient consultation process. ${ }^{35}$ The educator does not have to be present for this part of each consultation, but it is recommended that he or she is present periodically to observe. In practice, this will depend on the confidence of the educator in the competence of the students, but educators should be encouraged to let the students practise these skills independently of the educators to maximise studentdirected and peer learning opportunities. Students collaborate on stage 1 , data collection, but within this they have their own individual tasks, to promote positive interdependence, as described in the literature. ${ }^{32}$ Student A reviews the medical and nursing notes and Student B reviews the observation records, fluid balance records, anthropometric and biochemical results. Student A conducts the patient interview (stage 2), which involves introducing both students to the patient and explaining that Student A will be conducting a nutritional assessment of the patient, while Student B will be scripting/documenting what Student A is communicating (stage 3). Students collaborate on documentation in the dietetic record card (stage 4) and on devising the nutrition care plan (stage 5). The educator (who has already reviewed the patient's chart) then meets with the students at a prearranged time (if not already present) and Student A presents the case (stage 6). The educator then facilitates feedback on 
stages 1-6 between the two students, and any necessary amendments to the nutrition care plan are made (stage 7). Student A (i.e. the same student who conducted the patient interview) then implements the education/treatment plan with the patient while Student B and the educator observe, and the educator intervenes as necessary (stages $8 \& 9$ ). Both students work on documentation for the patient chart, and the dietetic record card (stage 10). Student A communicates with the relevant multidisciplinary team members (stage 11). The educator then facilitates reflection ${ }^{13,34}$ and peer feedback ${ }^{24}$ by both students on the case, away from the patient (stage 12). Students rotate being 'Student A' for consecutive patients.

Scenario 2 is used in a similar setting to scenario 1 , once students have gained confidence using scenario 1 . Students $\mathrm{A}$ and $\mathrm{B}$ are assigned separate patients, and work through stages $1-5$ of the patient consultation process independently. This is a demonstration of independent ability as discussed in the literature. ${ }^{11}$ At a pre-arranged time, the educator and Student B meet with Student A, who presents his/her patient case (stage 6). The educator then facilitates peer feedback on Student A's competence during stages 1-6 of the patient consultation process (stage 7). Student A next implements the education/treatment plan with the patient while Student $\mathrm{B}$ and the educator observe. The educator intervenes as necessary (stages $8 \& 9$ ). This process is then repeated with Student B. Both students individually work on documentation for their respective patient charts, and the dietetic record cards (stage 10), and communicate with the relevant multidisciplinary team members (stage 11). The educator then facilitates reflection and peer feedback with both students on both cases, away from the patient (stage 12). For scenario 2, students always observe each other for the implementation of the education/treatment plan, and both partake in the peer feedback session. The only exception is when the students are having one-to-one time with the educator, which should be scheduled regularly (at least two to three patients per week) to assure the educator of the students' individual competence.

Scenario 3 is used in an outpatient clinic setting. Students should rotate being 'Student A' (taking the lead) and 'Student B' (observing) for consecutive patients. As with a single student, if Student A is conducting the patient interview (stage 2), he or she will then 'pass the patient back' to the educator who may take over the consultation at that point. Students should begin by conducting stages $1-4$ of the patient consultation process. As they progress, they may conduct the entire consultation (stages 1-8) and the educator will only intervene where necessary. As part of the framework, Student A invites the educator to contribute at the end of the consultation. Between patient consultations, time permitting, there is a short reflection/discussion when Student A reflects on his/her consultation, and Student B is invited to give feedback/constructive criticism and read out all or the main points of the script that Student A communicated, to facilitate Student A's insight into his/her competence. The educator adds anything that the students may have missed.
All four sites reported that they would use the 2:1 model again, as reported previously in the literature. ${ }^{24}$ In keeping with the published literature, ${ }^{11,24,36}$ fears or concerns expressed by educators prior to introducing a collaborative model of PPE were largely not realised. The advisory group strongly recommended the provision of a more structured, stepwise, concrete framework based on educational theory for educators, to map the process of facilitating a 2:1 model, this recommendation resulting in the development of 'The Lynam Framework'. Although this exploratory pilot study of a 2:1 model in dietetics PPE was limited from a research perspective, in that formal interviews were not conducted, small numbers were used, students' perspectives were not examined and educators and students were not provided with specific training on a 2:1 model prior to PPE, the key recommendation made by the advisory group was implemented. Further research into the use of the 2:1 model during PPE and the ability of the framework to guide the implementation of this model has commenced. Full ethical approval has been granted for a longitudinal, mixedmethods study, following a cohort of dietetics students through their practice education over four years. This will examine the perceptions of educators and students on the use of the 2:1 model, implemented using 'The Lynam Framework'. The possibility of amending the framework for use in other health-related disciplines is also currently being explored.

\section{Funding source}

The authors declare that they did not receive funding for this research.

\section{Authorship}

A-ML designed and undertook the study, and wrote the initial draft of the paper, under the supervision of DC and CC. All authors critically reviewed, contributed to and approved the final version submitted for publication.

\section{Conflict of interest}

The authors declare that they have no conflict of interests.

\section{References}

1 DeClute J, Ladyshewsky R. Enhancing clinical competence using a collaborative clinical education model. Phys Ther 1993; 73: 683-9.

2 Lekkas P, Larsen T, Kumar S et al. No model of clinical education for physiotherapy students is superior to another: a systematic review. Aust J Physiother 2007; 53: 19-28.

3 EFAD. European dietetic competences and their performance indicators attained at the point of qualification and entry to the profession of dietetics. European Federation of Associations of Dietitians, 2009.

4 INDI. Guidelines for the Accreditation of Courses Leading to a Qualification in Human Nutrition and Dietetics. Ireland: Irish Nutrition and Dietetic Institute, 2005. 
5 Rindflesch AB, Dunfee HJ, Cieslak KR et al. Collaborative model of clinical education in physical and occupational therapy at the Mayo Clinic. J Allied Health 2009; 38: 132-42.

6 Zavadak KH, Konecky-Dolnack C, Polich S, van Volkenburg M. Collaborative models. Phys Ther Mag 1995; 3: 46-54.

7 Smith B, MacGregor J. What is collaborative learning? Wash Cent News 1993; 7: 3-11.

8 Lincoln MA, McAllister LL. Peer learning in clinical education. Med Teach 1993; 15: 17-25.

9 Martin M, Morris J, Moore A, Sadlo G, Crouch V. Evaluating practice education models in occupational therapy: comparing 1:1, 2:1 and 3:1 placements. Br J Occup Ther 2004; 67: 192200.

10 Morris J, Moore A. Management of student placements. In: Jones R, Jenkins F, eds. Developing the Allied Health Professional. Oxford, UK: Radcliffe Publishing Ltd, 2006; 51-64.

11 Baldry Currens J. The 2: 1 clinical placement model: review. Physiotherapy 2003; 89: 540-54.

12 Moore A, Morris J, Crouch V, Martin M. Evaluation of physiotherapy clinical educational models: comparing 1: 1, 2: 1 and 3: 1 placements. Physiotherapy 2003; 89: 489-501.

13 Morris J, Stew G. Collaborative reflection: how far do 2:1 models of learning in the practice setting promote peer reflection? Reflective Pract 2007; 8: 419-32.

14 Secomb J. A systematic review of peer teaching and learning in clinical education. J Clin Nurs 2008; 17: 703-16.

15 Briffa C, Porter J. A systematic review of the collaborative clinical education model to inform speech-language pathology practice. Int J Speech Lang Pathol 2013; 15: 564-74.

16 Rodger S, Webb G, Devitt L, Gilbert J, Wrightson P, McMeeken J. Clinical education and practice placements in the allied health professions: an international perspective. J Allied Health 2008; 37: $53-62$

17 Ladyshewsky R. Peer-assisted learning in clinical education: a review of terms and learning principles. J Phys Ther Educ. 2000; 14: 15-22.

18 Roberts NJ, Brockington S, Doyle E et al. Pilot study of an innovative model for clinical education in dietetics. Nutr Diet 2009; 66: 39-46.

19 Grundy K. Peer placements: it's easier with two. Bull R Coll Speech Lang Ther 1994; 510: 10-1.

20 Triggs Nemshick M, Shepard KF. Physical therapy clinical education in a 2:1 student-instructor education model. Phys Ther 1996; 76: 968-81.

21 Baldry Currens J, Bithell CP. The 2:1 clinical placement model: perceptions of clinical educators and students. Physiotherapy 2003; 89: 204-18.
22 Parker A, Kersner M. New approaches to learning on clinical placement. Int J Lang Commun Disord 1998; 33 (Suppl.): 25560.

23 Roberts NJ, Brockington S, Doyle E et al. Innovative model for clinical education in dietetics. Nutr Diet 2009; 66: 33-8.

24 Dawes J, Lambert P. Practice educators' experiences of supervising two students on allied health practice-based placements. J Allied Health 2010; 39: 20-7.

25 O'Connor A, Cahill M, McKay EA. Revisiting 1:1 and 2:1 clinical placement models: student and clinical educator perspectives. Aust Occup Ther J 2012; 59: 276-83.

26 Johnson DW, Johnson RT. New developments in social interdependence theory. Genet Soc Gen Psychol Monogr 2005; 131: 285-358.

27 Frey JH, Fontana A. The group interview in social research. Soc Sci J 1991; 28: 175-87.

28 Vaughn S, Schumm JS, Sinagub J. Focus Group Interviews in Education and Psychology. Thousand Oaks, CA: SAGE Publications, Inc., 1996; 15-7.

29 Glaser B. The constant comparative method for qualitative analysis. In: Glaser B, Strauss A, eds. The Discovery of Grounded Theory: Strategies for Qualitative Research. Chicago: Aldine, 1967; 101-16.

30 Burnard P. A method of analysing interview transcripts in qualitative research. Nurse Educ Today 1991; 11: 461-6.

31 Ladyshewsky RK. Enhancing service productivity in acute care inpatient settings using a collaborative clinical education model. Phys Ther 1995; 75: 503-10.

32 Johnson DW, Johnson RT. An educational psychology success story: social interdependence theory and cooperative learning. Educ Res 2009; 38: 365-79.

33 Rapoport L, Pearson D. Changing Health Behaviour. In: Thomas B, Bishop J, eds. Manual of Dietetic Practice. London: Blackwell Publishing, 2007; 46-58.

34 Fade S. Reflection and assessment. In: Tate S, Sills M, eds. The Development of Critical Reflection in the Health Professions. London: Higher Education Authority, 2004; 96-100.

35 Hakel-Smith N, Lewis NM. A standardized nutrition care process and language are essential components of a conceptual model to guide and document nutrition care and patient outcomes. J Am Diet Assoc 2004; 104: 1878-84.

36 Ladyshewsky RK, Barrie SC, Drake VM. A comparison of productivity and learning outcome in individual and cooperative physical therapy clinical education models. Phys Ther 1998; 78: 1288-98. discussion 99-301. 